S. Frederiksen

\title{
The SSCL Framework Software Plans
}

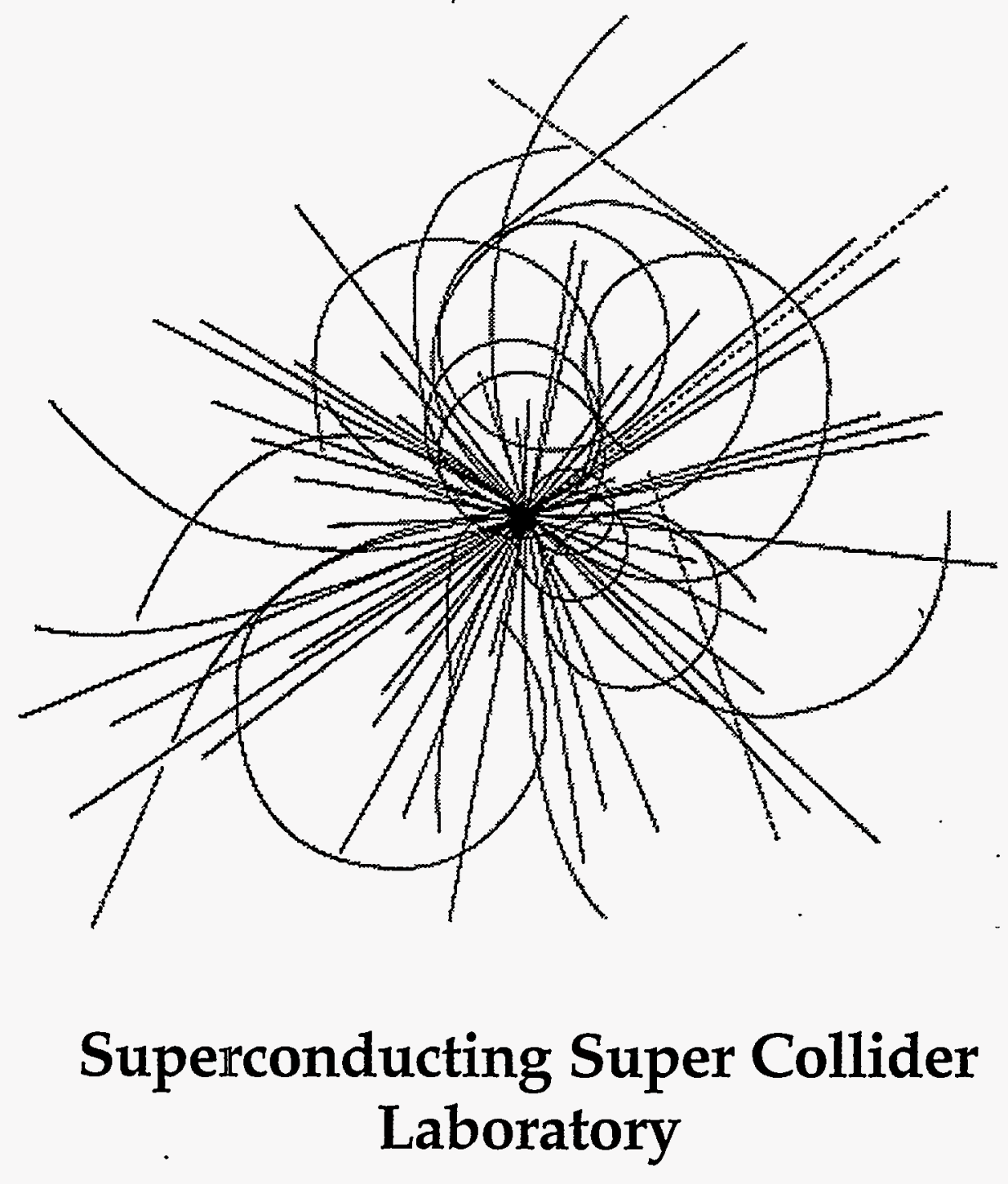

APPROVED FOR RELEASE OR

PUBLICATION - O:R. PATENT GROUP BY.....50 


\section{Disclaimer Notice}

This report was prepared as an account of work sponsored by an agency of the United States Govemment. Neither the United States Govemment or any agency thereof, nor any of their employees, makes any warranty, express or implied, or assumes any legal liability or responsibility for the accuracy, completeness, or usefulness of any information, apparatus, product, or process disclosed, or represents that its use would not infringe privately owned rights. Reference herein to any specifie commercial product, process, or service by trade name, trademark, manufacturer, or othenwise, does not necessarily constltute or imply its endorsement, recommendation, or favoring by the United States Govemment or any agency thereof. The views and opinions of authors expressed herein do not necessarily state or reflect those of the United States Govemment or any agency theroof.

Superconducting Super Collider Laboratory is an equal opportunity employer. 


\section{DISCLAIMER}

Portions of this document may be illegible in electronic image products. Images are produced from the best available original document. 


\title{
The SSCL Framework Software Plans*
}

\author{
S. Frederiksen \\ Superconducting Super Collider Laboratory ${ }^{\dagger}$ \\ 2550 Beckleymeade Ave. \\ Dallas, TX 75237, USA
}

December 1993

- "Presented at the Third International Workshop on Software Engineering Artificial Intelligence and Expert Systems for High Energy and Nuclear Physics.

tOperated by the Universities Research Association, Inc., for the U.S. Department of Energy under Contract No. DE-AC35-89ER40486. 


\author{
Soren G. Frederiksen \\ Superconducting Super Collider \\ Dallas, TX U.S.A.
}

\begin{abstract}
In about ten years the Superconducting Super Collider Laboratory (SSCL) will be producing 40 $\mathrm{TeV}$ proton-proton interactions. The size and scale of the effort demands new approaches to design and develop software used by the experimental collaborations. The Physics Research Division Computing Department (PRCD) of the SSCL is developing (in collaboration with the Solenoidal Detector Collaboration (SDC) and Gamma, Electron and Muon (GEM) collaboration) a support system which will be used to build and run the collaboration software. It will be used for simulating the events needed for detector development and for the analysis of these complicated events. The plans and status of this program will be discussed.
\end{abstract}

\title{
1. Introduction
}

A standardized environment or set of framework services is required to support the various tools, utilities, application programs and subroutines that will be developed by the GEM and SDC experimental collaborations. The Reference Models developed by the U.S. Navy's Project Support Environment Standards Working Group (PSESWG) (Reference 1), a working group in the Next Generation Computing Resources (NGCR) program, and the National Institute of Standards and Technology (NIST) (Reference 2) were heavily referenced when developing the plans for the Framework Software project. These Reference Models define the Framework services as the services which comprise the underlying infrastructure of an environment. In this context Services refer to an environment's capabilities or is an abstract description of the work being done. The purpose of the Framework Software project is to develop the Framework Software services that will be used by the SSC collaborations.

\section{Framework Software}

The Framework Software will be developed to run on the PRCD supported platforms which currently include most major UNIX vendors (DEC, HP, IBM, SGI and SUN). The software will always reflect an open system concept, to ensure that the software will be able to migrate as the technology changes. The distributed nature of SSCL computing requires that this software be able to run in a distributed computing environment, and will also allow for a parallel processing environment. The software will be written in a modular and expandable manner using Object Oriented Analysis, Object Oriented Design, and Object Oriented Programing.

The PSESWG reference model has two basic categories of services, the Framework Services and the End-User Services. The End-User Services are further subdivided into Technical Engineering, Technical Management, Project Management, and Support Services. Figure 1 shows the relationships among these 5 service groups. The Framework Software forms the central core with relationships to all the other services. The Support Services underlie and support all the other services. 


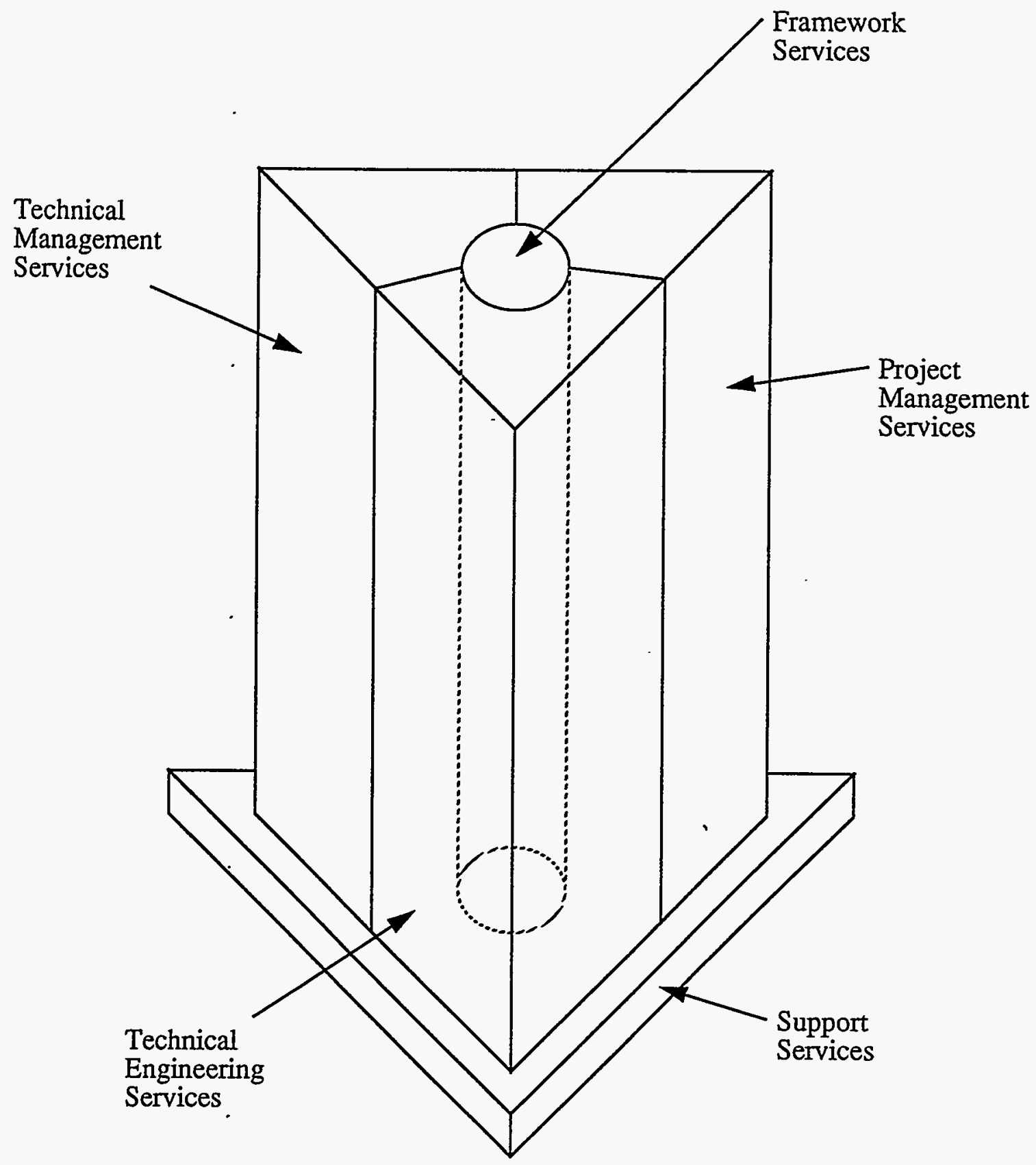

Figure 1. Service Groups relationships. 
The standardized Framework services and tools that need to be developed are:

- Operating System services: The services normally associated with the operating system.

- Object Management services: The services responsible for the definition, storage, maintenance, management, and access of object entities and the relationships among them.

- Policy Enforcement services: The services which take care of security enforcement, integrity monitoring, and various object management functions.

- Process Management services: The services responsible for the definition and the computer-assisted management of project development activities.

- Communication services: The services which provides a standard communication mechanism that is used for inter-tool and inter-service communication.

- User Interface services: The services which provide for the integration of the object management system, the process management services and the tools.

- Framework Administration services: The services responsible for configuring and administering the Framework Environment.

- A C++ Class Library for use by the Framework Software. It is assumed that the object oriented programming will be done using $\mathrm{C}++$.

- An Interface Definition Language (IDL).

- A Data Definition Language (DDL).

In order to facilitate the development of the Framework Software a complete Software Development Environment (SDE) will also be required. This SDE is referred to as the Physics Research Integrated Development Environment (PRIDE) and is described in more detail in Reference 3. The scope of this project will also include the development of the PRIDE.

\section{Plans}

The Framework Software project is a joint GEM/SDC/PRCD project, and requires the cooperation of Physicists and Computer Specialists. The final integrated computing environment that this project will develop will be used by both collaborations.

The Framework Software development will involve the following steps:

1 A review of the Framework Reference Models (Reference 1 and 2) to establish their relevance for the Framework Software.

2 Establish Functional Requirements. This will require interviews of the collaboration physicists in order to determine their requirements. It is anticipated that this will only be the preliminary requirements which will be refined during follow-on activities of the project and as new versions of the Framework Software are developed.

3 Develop system design. The system design step will also require Pilot Projects and Prototypes to help refine the Function Requirements and the System Design. These Pilot Projects will be used by the collaboration physicists to give them a feel for what the final production system will be like. It is anticipated that the System Design will also be refined during follow-on steps.

4 Develop the Framework Software development plan. 
5 Develop the requirements specifications.

6 Develop the test plans specifications for the Framework Software. Pilot projects may also be required as part of the Framework software development plan.

7 Develop the software design.

8 Code development and/or integration of software.

9 Final integration and testing of the production system.

These steps will result in a final work Framework Software program. The procedure will then repeat itself in order to develop evolutionary versions of the Framework Software program.

In order to compress the development time and to implement a workable environment for the physicists as soon as possible, the first few steps will also involve the use and testing of IBM's SEE Pathfinder. SEE Pathfinder is a fully integrated Software Development Environment developed by IBM's Software Engineering Technology (SET) group. The SEE Pathfinder will be evaluated as a candidate for the PRIDE, and will be used to help in the first phase of the Framework Software development. SEE Pathfinder is the integration of a number of programs in an IBM Workbench (or HP Softbench) environment for use in the development of software. It has integrated both upper and lower CASE tools.

The PRIDE development will involve the following steps:

1 Establish Functional Requirements. After establishing the Functional Requirements the SEE Pathfinder will be evaluated to see if it is a candidate solution for the PRIDE. If it is determined that the SEE Pathfinder is not the appropriate candidate for the PRIDE then the remaining steps will be followed.

2 Develop system design. It is anticipated that the System Design will also be refined during follow-on steps.

3 Develop the PRIDE development plan.

4 Develop the requirements specifications.

5 Develop the test plans specifications for the PRIDE. Pilot projects may also be required as part of the PRIDE development plan.

6 Develop the software design.

7 Code development and/or integration of software. ,

8 Final integration and testing of the production system.

The Framework Software project has just started down the trail of developing the software that will be used by the SSCL collaborations. This software should meet and exceed the requirements of the collaborations and will continue to evolve and be used well into the 21 st century.

\section{References}

1. PSESWG, Next Generation Computing Resources, Reference Model for Project Support Environment, Version 1.0, March 1, 1993.

2. NIST \& ECMA, Reference Model for Frameworks of Software Engineering Environments, NIST Special Publication 500-211, August, 1993.

3. Jackie Burton \& Laird Cormell, Physics Research Integrated Development Environment (PRIDE), These Proceedings. 